\title{
BLOG NO ENSINO DA RESSUSCITAÇÃO CARDIOPULMONAR: UMA FERRAMENTA PARA A FORMAÇÃO DO ENFERMEIRO
}

\section{BLOG IN THE TEACHING OF CARDIOPULMONARY RESUSCITATION: A TOOL FOR NURSING TRAINING}

\section{BLOG EN LA ENSEÑANZA DE LA REANIMACIÓN CARDIOPULMONAR: UNA HERRAMIENTA PARA LA FORMACIÓN EN ENFERMERÍA}

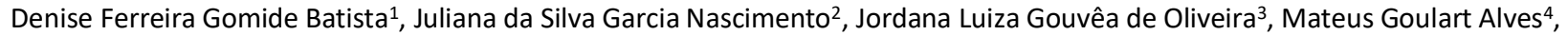
Marcelo Donizeti Silva5, Maria Celia Barcellos Dalri6.

\section{RESUMO}

Objetivo: Desenvolver e validar um blog para o ensino e a aprendizagem da ressuscitação cardiopulmonar do adulto voltado à formação do enfermeiro. Método: Pesquisa aplicada, de produção tecnológica, que abordou o desenvolvimento de um blog sobre a ressuscitação cardiopulmonar do adulto no ambiente intra e extra-hospitalar para enfermagem. Na elaboração, cumpriram-se as fases de análise; design; desenvolvimento, implementação e avaliação do blog. A validação desse ambiente virtual de aprendizagem envolveu 11 profissionais enfermeiros da área de urgência e emergência e três especialistas de informática, totalizando 14 participantes. Resultados: Elaborou-se uma ferramenta virtual pedagógica de ensino e aprendizagem, denominada "Blog da Ressuscitação Cardiopulmonar". A avaliação dos três especialistas em informática abordou os domínios; tempo de resposta, qualidadede, interface e ferramentas e recursos, abrangendo 33 critérios, considerados excelentes pela maioria. Os experts em enfermagem avaliaram 32 critérios entre aspectos educacionais, a interface do ambiente virtual e os recursos didáticos, apontados, predominantemente, como excelentes. Conclusão: Neste estudo, elaborou-se e validou-se um blog para o ensino da ressuscitação cardiopulmonar de adultos, representando um arcabouço de evidências científicas atualizadas, fidedignas, interativas e tecnológicas para a enfermagem, que poderá ser replicado em outros ambientes de aprendizagem.

Descritores: Reanimação Cardiopulmonar; Educação em Enfermagem; Estratégias; Aprendizagem; Blog.

\section{ABSTRACT}

Objective: to develop and validate a blog for teaching and learning adult cardiopulmonary resuscitation to nurses. Method: applied research of technological production, which addressed the development of a blog about adult cardiopulmonary resuscitation in the intra and extra-hospital environment focused on nursing. For the elaboration, the analysis phases were accomplished; design; development, implementation and evaluation of the blog. The validation of this virtual learning environment involved 11 professional nurses in the urgency and emergency area and three computer specialists, totaling 14 participants. Results: A virtual teaching and learning tool was developed, named "Blog of Cardiopulmonary Resuscitation". The evaluation of the three computer experts covered the following domains: response time, interface quality and tools and resources, totaling 33 criteria considered excellent by most. The nursing experts evaluated 32 criteria between educational aspects, the interface of the virtual environment and didactic resources, which were predominantly indicated as excellent. Conclusion: This study designed and validated a blog for teaching adult cardiopulmonary resuscitation, representing an updated, reliable, interactive and technological scientific evidence for nursing, which can be replicated in other learning environments.

Descriptors: Cardiopulmonary Resuscitation; Nursing Education; Strategies; Learning; Blog.

\section{RESUMEN}

Objetivo: desarrollar y validar un blog para enseñar y aprender la reanimación cardiopulmonar de adultos para capacitar a los enfermeros. Método: investigación aplicada, de producción tecnológica, que abordó el desarrollo de un blog sobre reanimación cardiopulmonar para adultos en entorno intra y extrahospitalario, en enfermería. Para la elaboración, se realizaron las fases de análisis, diseño, desarrollo, implementación y evaluación del blog. La validación de este entorno virtual de aprendizaje involucró a 11 enfermeros profesionales del área de urgencias y emergencias y tres especialistas en informática, con un total de 14 participantes. Resultados: se desarrolló una herramienta virtual de enseñanza y aprendizaje, llamada "Blog de reanimación cardiopulmonar". La evaluación de los tres expertos en informática cubrió los dominios; tiempo de respuesta, calidad de interfaz y herramientas y recursos, cubriendo 33 criterios, considerados excelentes por la mayoría. Los expertos en enfermería evaluaron 32 criterios entre los aspectos educativos, la interfaz del entorno virtual y los recursos didácticos, que se indicaron predominantemente como excelentes. Conclusión: este estudio diseñó y validó un blog para la enseñanza de la reanimación cardiopulmonar para adultos, que representa un marco de evidencia científica actualizada, confiable, interactiva y tecnológica para enfermería, que puede replicarse en otros entornos de aprendizaje.

DESCRIPTORES: Reanimación Cardiopulmonar; Educación en Enfermería; Estrategias; Aprendizaje; Blog

${ }^{1}$ Mestre em Enfermagem. ${ }^{2}$ Mestre. Doutoranda do programa de doutorado fundamental da Escola de Enfermagem de Ribeirão Preto. ${ }^{3}$ Mestranda do programa de mestrado Fundamental da Escola de Enfermagem de Ribeirão Preto. ${ }^{4}$ Mestre. Doutorando na Universidade de Franca. ${ }^{5}$ Educador físico, doutorando do programa de doutorado fundamental da escola de enfermagem de Ribeirão Preto. ${ }^{6}$ Doutora. Docente no curso de graduação em enfermagem na Escola de Enfermagem de Ribeirão Preto. 


\section{INTRODUÇÃO}

A atualidade está permeada por uma revolução tecnológica social proveniente do uso em massa de novos recursos para propagar a informação, por meio,principalmente,da internet na vida cotidiana dos indivíduos, da proliferação de redes sociais e dos blogs educativos ${ }^{(1-2)}$.

O blog é considerado um ambiente virtual estruturado em pequenos blocos, denominados "posts", que abrangem textos, imagens e objetos de mídia, bem como a presença de links para navegação do usuário. ${ }^{3}$ Essa ferramenta digital pode contemplar $\mathrm{o}$ processo de ensino $\mathrm{e}$ aprendizagem, e representar um eixo pedagógico transversal atrativo e de fácil acesso para estudantes e profissionais ${ }^{(1-2)}$.

Emergindo também na educação em saúde, o blog é representando por um modelo de inovação tecnológico disruptivo, ou seja, um produto educacional simples, conveniente e acessível para o usuário, que promete acompanhar e superar os livros produzidos em massa e as palestras tradicionais para educação em saúde ${ }^{(4)}$.

Especificamente, na enfermagem, dentre os desafios para a ruptura do paradigma tradicional de ensino ainda vigentes, estão a adaptação às demandas de uma nova geração de alunos, com expectativas de aprendizado diferenciadas, caracterizadas como "geração Net", e a dificuldade de apropriação, por parte do corpo docente, das tecnologias envoltas no processo de ensino e aprendizagem ${ }^{(5)}$.

Nessa perspectiva, adotar a utilização de blogs como ferramenta complementar para o ensino na enfermagem pode ocasionar mudanças significativas em como, onde e quando os alunos terão acesso aos materiais educativos pertinentes ao desenvolvimento de competências clínicas, principalmente para elucidação de temáticas complexas, como a ressuscitação cardiopulmonar(RCP) $)^{(6)}$.

No processo de ensino e aprendizagem da RCP para enfermagem, tem-se observado, com frequência, a adoção de cursos e treinamentos que não abordam estratégias inovadoras e tecnológicas, impactando, negativamente, no desenvolvimento de conhecimentos. habilidades e atitudes, e na retenção desse aprendizado para estudantes e profissionais da enfermagem ${ }^{(7)}$.

Apesar da utilização de blogs para o ensino da RCP ser recomendada pela literatura e pela American Heart Association (AHA), principal entidade voltada à disseminação do conhecimento sobre doenças cardiovasculares e $R C P$, estudos científicos, bem elaborados metodologicamente, que se proponham a desenvolver blogs são ainda incipientes ${ }^{(8-10)}$.

Considerando a potencialidade do blog como recurso educacional e ferramenta virtual inovadora para viabilizar a aprendizagem da RCP em enfermagem, neste estudo, objetivou-se desenvolver e validar um blog para o ensino e a aprendizagem da RCP do adulto voltado à formação do enfermeiro.

\section{MÉTODO}

Trata-se de pesquisa aplicada, de produção tecnológica, que abordou o desenvolvimento de um blog sobre a RCP do adulto, no ambiente intra e extra-hospitalar, para o processo de ensino e aprendizagem de estudantes de graduação em enfermagem.

A pesquisa foi desenvolvida, na Escola de Enfermagem de Ribeirão Preto, da Universidade de São Paulo (USP) e obteve como população 11 profissionais enfermeiros, experts da área de urgência e emergência e/ou docentes em enfermagem, que ministram conteúdo dessa natureza, para avaliação do ambiente virtual de aprendizagem (AVA) blog, e três especialistas na área de informática, totalizando 14 participantes.

Os especialistas foram identificados pormeio da plataforma curricular Lattes, embasando-se nos critérios de Fehring ${ }^{(11)}$ para seleção, que considera: 4 pontos para titulação de Mestre em Enfermagem; 1 ponto para titulação de Mestre em Enfermagem, com dissertação na área de interesse do estudo; 2 pontos para tese de doutorado na área do estudo; 1 ponto para prática clínica de, pelo menos, 1ano na área de interesse;2pontos para certificado de prática clínica (especialização), na área de interesse; 2 pontos para publicação de pesquisa relevante para a área de interessee; 2 pontos para publicação de artigo sobre o tema em periódico de referência. Consideraram-se critérios de inclusão, a saber: ser enfermeiro, especialista na área de urgência e emergência ou docente nessa temática, e/ou ser profissional especialista na área da informática com ênfase na elaboração de AVA, e a obtenção de somatória mínima de 5 pontos, de acordo com os critérios denominados porFehring ${ }^{(11)}$.

Foram excluídos os profissionais que estivessem em período de férias ou afastamento no período definido pelo pesquisador para a avaliação dos instrumentos e aqueles que não 
realizaram a avaliação dentro do período determinado de 15 dias, após o recebimento dos instrumentos e aceite para avaliação.

O AVA foi produzido por uma equipe composta por um programador de sistemas e web designer, e pela pesquisadora. Dessa forma, cumpriram-se as seguintes fases: análise, design, desenvolvimento, implementação e avaliação(12).

Na primeira fase, de análise, realizou-se revisão de literatura, no período de março a junho de 2018, nas bases de dados PubMed $^{\circledast} /$ MEDLINE $^{\circledR}$, Literatura LatinoAmericana e do Caribe em Ciências da Saúde (LILACS), Scopus, Cumulative Index to Nursing and Allied Health Literature (CINAHL) e Web of Science, e nos documentos referentes às diretrizes internacionais de RCP e atendimento cardiovascular de emergência (ACE) da American Heart Association (AHA) $)^{(8)}$ para elaboraro roteiro pertinente ao conteúdo do blog proposto, baseado em evidências científicas.

Em seguida, o conteúdo foi dividido em módulos sequenciais e complementares, estabelecendo-se a seguinte estrutura: conteúdo do módulo; referências; links/material para estudo dirigido; fórum/chats e e-mail. Após, procedeu-se à elaboração dos objetivos educacionais, a partir da taxonomia de Bloom, que considera os domínios cognitivo, afetivo e psicomotor para aprendizagem. ${ }^{(13)}$.

Adotaram-se os seguintes objetivos de aprendizagem referentes ao domínio cognitivo: atualizar permanentemente as diretrizes de RCP; compreender a definição e os mecanismos da parada cardiorrespiratória (PCR); conhecer a anatomia e a fisiologia cardiocirculatória e respiratória; conhecer os fatores de risco para PCR; entender os ritmos de PCR; compreender a cadeia de sobrevivência intra e extra-hospitalar; identificar e conhecer os materiais e equipamentos utilizados na PCR (carrinho de emergência, dispositivos para via aérea $e$ desfibrilador); e compreender a ciência da simulação realística.

Os objetivos de aprendizagem que compuseram o domínio psicomotor foram: educar para adquirir habilidades e aquisição de conhecimento sobre RCP em adultos; e provocar mudanças no comportamento do aprendiz, para o atendimento da PCR em adultos de alta qualidade. Já para o domínio afetivo, abordaram-se as seguintes pretensões: perceber a importância do estudo do tema para sua vida profissional; influenciar na atitude favorável à busca e à aquisição de conhecimentos; compartilhar respeito na relação interpessoal, respondendo sempre aos outros participantes quando questionado e recebendo as contribuições dos outros participantes de forma analítica; proporcionar comunicação bi ou multidirecional com a interação aluno- conteúdo, usuáriosconteúdo e especialistas no tema.

$\mathrm{Na}$ segunda fase, de design, ocorreram a reformulação e a ampliação de todo material didático determinado para o AVA, selecionandose os seguintes módulos: $O$ que é $P C R$; fisiopatologia da PCR; fatores de risco para PCR; ritmos da PCR; cadeia de sobrevivência (intra e extra-hospitalar); desfibrilador; materiais $\mathrm{e}$ equipamentos para o atendimento da PCR (medicamentos, carrinho de emergência e dispositivos de vias aéreas); registro da PCR; atendimento simulado (ambiente intra e extrahospitalar) e pastas de conteúdo.

Elaborou-se, ainda, nesta fase, um storyboard para a definição dos elementos primários de tela, que compuseram o Blog da RCP, com a finalidade de orientar o processo de desenvolvimento pela profissional de web designer, considerando os seguintes elementos para o layout: fonte ("Libre Franklin", "Helvetica Neue", "Helvética", "Arial"e"Sans-Serif"); tamanho da fonte 14; esquema de cores branco,cinza e vermelho;tamanho da tela adaptativo ao dispositivo; tamanho médio dos arquivos de vídeo (vídeos alocados - on demand na plataforma Youtube); tamanho dos arquivos de imagem (arquivos de imagem com resolução de 72dpis, nos formatos .JPG e .PNG - compactados - com tamanho máximo de 200 KB); elementos de layout utilizado (CMS Word Pressver são gratuitos, utilizando-se template gratuito Twenty Seventeen,versão2.2); localização do menu na horizontal, no topo da página; barra de rolagem vertical.

$\mathrm{Na}$ terceira fase, de desenvolvimento, estruturou-se o conteúdo para o processo de ensino e aprendizagem da RCP em adultos, associando imagens, vídeos de atendimento de PCR intra e extra-hospitalar, realizados por pesquisadores do programa de pós-graduação, da Escola de Enfermagem de RibeirãoPreto, da USP e fotografias pertencentes ao arquivo pessoal do pesquisador, além da disponibilização de links úteis, na intencionalidade de tornar o blog dinâmico, interativo e embasado em evidências científicas confiáveis.

$\mathrm{Na}$ quarta fase, a implementação, 
desenvolveram-se o AVA baseado na web e o blog em versão Word Press, configurada como plataforma utilizada para embasar a construção de blogs, com versões de hospedagem e upgrades gratuitos e pagos.Por fim, a última fase de elaboração do blog, a avaliação,foi realizada por especialistas em tecnologia de informática e experts em enfermagem, aplicando-se dois instrumentos validados ${ }^{(14)}$.

$O$ instrumento destinado aos especialistas em informática ${ }^{14}$ contempla três domínios analisados em uma escala do tipo Likert com pontuação de 1 a 3, significando insatisfatório (1 ponto), satisfatório ( 2 pontos) e excelente ( 3 pontos). Nos tópicos avaliados como insatisfatório, orientou-se comentar ou justificar no campo "Considerações", visando à realização de melhorias e adequações no AVA Blog da RCP.

$O$ primeiro domínio desse instrumento referiu-se ao tempo de resposta, utilizado para avaliar questões de navegabilidade, acessibilidade, feedback do sistema ao usuário. 0 segundo domínio abrangeu a qualidade de interface para avaliar os aspectos visuais ou design do AVA, como cores, menu, botões e outros elementos. O terceiro domínio, ferramentas e recursos, avaliou a forma, a apresentação e o funcionamento das ferramentas do sistema, como, por exemplo, fórum, e-mail elinks.

O segundo instrumento ${ }^{(14)}$ foi destinado aos experts de enfermagem e dividido em três domínios. No primeiro, denominado "aspectos educacionais", objetivou-se avaliar o tema proposto; a coerência dos objetivos educacionais,

textos e hipertextos; a autonomia do usuário; e os recursos didáticos empregados. No segundo domínio, "interface do ambiente" voltou-se à avaliação de itens como navegabilidade, acessibilidade e design do ambiente. No terceiro domínio, "recursos didáticos", avalia-se a interatividade do sistema, a funcionalidade dos recursos didáticos e os recursos de tela. Para envio online dos formulários de avaliação, utilizou-se o aplicativo virtual Google Docs.

Os dados obtidos foram organizados por avaliador e por questões em números absolutos e porcentagem, exportados em forma de planilha para o Microsoft Excel $^{\circledast}$ 2013, com dupla digitação, por dois pesquisadores diferentes, analisando-os por meio de estatistica descritiva no programa Statistical Package for the Social Sciences (SPSS), versão 23.

Para cumprimento dos preceitos éticos, este estudo foi submetido e aprovado pelo Comitê de Ética em Pesquisa da Escola de Enfermagem de Ribeirão Preto da USP, protocolo CAAE:99791118.4.0000.5393, seguindo a resolução 466/2012 do Conselho Nacional de Saúde (CNS), com aceite dos participantes por Termo de Consentimento Livre online.

\section{RESULTADOS E DISCUSSÃO}

Elaborou-se o AVA, no formato blog,
denominado Blog
(http://www.blogdarcp.com.br). Após digitar o
endereço do AVA, o usuário teve acesso à página
inicial do blog, como demonstrado na Figura 1.

Figura 1 - Tela inicial do Blog da RCP. Ribeirão Preto-SP, 2019.

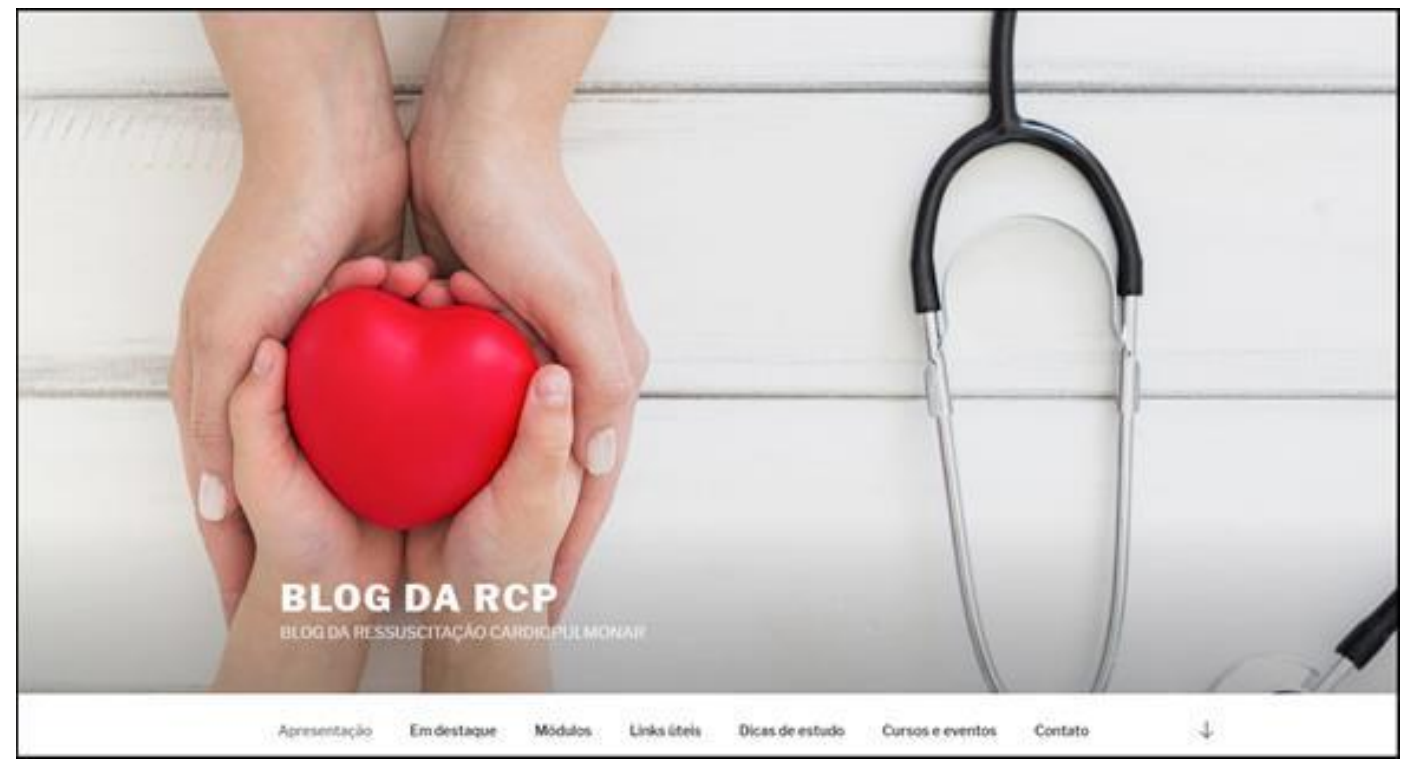

Fonte: dados obtidos do estudo, 2020 
O menu do blog foi exposto, horizontalmente, na parte superior da tela, compreendendo os seguintes botões: Apresentação, Em destaque, Módulos, Links úteis, Dicas de estudo, Cursos e eventos, e Contato.

A proposta da primeira tela, a apresentação do blog, foi permitir uma chamada visual que correspondesse à identidade do tema. O botão "Em destaque" garantiu acesso aos posts publicados pelos coordenadores do blog, com temas e atualizações sobre a ciência da RCP.

Nos conteúdos presentes em "Módulos", o usuário desenvolvia o conhecimento sobre o atendimento da PCR no adulto, conferindo, em cada uma das unidades, informações baseadas na diretriz da American Heart Association ${ }^{(8)}$ e vídeos educativos sobre o atendimento de uma PCR. No final do conteúdo de cada módulo, estava disponível uma relação de referências atualizadas sobre o assunto estudado e também links externos, para sustentar e validar as informações. Os botões "links úteis" e "dicas de estudo" reuniam todos os links externos selecionados para estudo da RCP.

O botão "cursos e eventos," abrangia cursos e eventos que aconteceriam, no decorrer do ano. Congressos nacionais e internacionais de relevância na área seriam listados para que os usuários pudessem estar em constante atualização. Já o botão "Contato" configurou uma forma dinâmica, para que os usuários contatassem osresponsáveis pelo blog, contendo nome, e-mail, assunto e conteúdo da mensagem que seria direcionada para o e-mail blogrcpusp@gmail.com.

Quanto à avaliação e à validação do AVA Blog da RCP em face e conteúdo, identificou-se, primeiramente, o perfil dos especialistas selecionados,segundo sua área de formação,tempo de experiência profissional na área, maior titulação e principal atividade atual.

Os especialistas em informática apresentaram formação profissional e atividade atual distintas, a saber: Bacharel em computação, analista de sistema e tecnologia da Informação, exercendo, atualmente, funções de consultoria, análise e desenvolvimento de sistemas e desenvolvimento de web. O menor tempo de experiência foi de 8 anos e o maior, 20 anos, e a maior titulação foi de especialista.

Quanto ao perfil dos experts em enfermagem, o menor tempo de experiência profissional foi 7 anos e o maior tempo, 36 anos. A menor titulação foi Mestrado e a maior PósDoutorado, sendo a maioria doutores na área de urgência e emergência, e a principal atividade exercida na atualidade foi a docência em enfermagem.

Na Tabela 1, expõe-se a avaliação do blog proposto pelos especialistas em informática, referente aos domínios "tempo de resposta", "qualidade de interface" e "ferramentas e recursos", apontando o número e percentual de profissionais que considerou insatisfatório, satisfatório ou excelente cada critério abordado.

Tabela 1 - Avaliação do Blog da RCP, segundo os especialistas em informática, considerando seus domínios. Ribeirão Preto-SP, 2019. $(n=3)$

\begin{tabular}{lccc}
\hline \hline Domínios e critérios & $\begin{array}{c}\text { Avaliação } \\
\text { Insatisfatório } \\
\mathbf{n}(\%)\end{array}$ & $\begin{array}{c}\text { Satisfatório } \\
\mathbf{n}(\%)\end{array}$ & Excelente $\mathbf{n}(\%)$ \\
\hline Domínio 1: tempo de resposta & & & $2(66,7)$ \\
Navegabilidade & 0 & $1(33,3)$ & $3(100)$ \\
Acessibilidade & 0 & 0 & $3(100)$ \\
Processo de inicialização & 0 & 0 & $2(66,7)$ \\
Exibir próxima tela & 0 & $1(33,3)$ & $2(66,7)$ \\
Exibir tela anterior & 0 & $1(33,3)$ & $2(66,7)$ \\
Domínio 2: qualidade de interface & & $1(33,3)$ & $3(100)$ \\
Simulação & 0 & 0 & $2(66,7)$ \\
Uso do espaço & 0 & $1(33,3)$ & $3(100)$ \\
Formato das telas & 0 & 0 & $2(66,7)$ \\
Facilidade de uso & 0 & $1(33,3)$ & $1(33,3)$ \\
Design & 0 & $2(66,7)$ & $3(100)$ \\
Botões de navegação & 0 & 0 & $2(66,7)$ \\
Esquema de cores & 0 & $1(33,3)$ & $1(33,3)$ \\
Figuras & 0 & $2(66,7)$ & $1(33,3)$ \\
Fotos & 0 & $2(66,7)$ & "continua na página seguinte"
\end{tabular}




\begin{tabular}{lccc}
\hline \hline Domínios e critérios & \multicolumn{1}{c}{$\begin{array}{c}\text { Avaliação } \\
\text { Insatisfatório } \\
\mathbf{n}(\%)\end{array}$} & $\begin{array}{c}\text { Satisfatório } \\
\mathbf{n}(\%)\end{array}$ & Excelente $\mathbf{n}(\%)$ \\
\hline Sons & 0 & $2(66,7)$ & $1(33,3)$ \\
Textos & 0 & 0 & $3(100)$ \\
Mensagens de erro & 0 & $1(33,3)$ & $2(66,7)$ \\
Menu (disposição) & 0 & $1(33,3)$ & $2(66,7)$ \\
Menu (sequência) & 0 & $1(33,3)$ & $2(66,7)$ \\
Identificação das páginas & 0 & $1(33,3)$ & $2(66,7)$ \\
Botão de som & 0 & $2(66,7)$ & $1(33,3)$ \\
Links internos & 0 & $2(66,7)$ & $1(33,3)$ \\
Links externos & 0 & $2(66,7)$ & $1(33,3)$ \\
Botões (destaque) & 0 & $1(33,3)$ & $2(66,7)$ \\
Fonte & 0 & $1(33,3)$ & $2(66,7)$ \\
Cabeçalhos & 0 & $1(33,3)$ & $2(66,7)$ \\
Ícones & 0 & 0 & $3(100)$ \\
Densidade informacional & 0 & $1(33,3)$ & $2(66,7)$ \\
Home & 0 & $1(33,3)$ & $2(66,7)$ \\
Domínio 3: ferramentas e recursos & & & $1(33,3)$ \\
Fórum (chats) & $1(33,3)$ & $1(33,3)$ & $3(100)$ \\
E-mail & 0 & 0 & $2(66,7)$ \\
Links & 0 & $1(33,3)$ & \\
\hline \hline
\end{tabular}

Fonte: dados obtidos do estudo, 2020.

Um total de 33 critérios foi avaliado pelos especialistas em informática quanto ao AVA Blog da RCP. O domínio referente ao tempo de resposta abordou cinco critérios, considerados excelentes pela maioria dos avaliadores. Nenhum critério foi apontado como insatisfatório. O domínio qualidade da interface abrangeu 25 critérios, e a maioria dos avaliadores também consideram excelentes. Já no domínio ferramentas e recursos, composto por três critérios, a maioria dos avaliadores considerou-os excelentes, porém, o item "fórum" foi considerado insatisfatório e passível de melhorias.Os especialistas em informática sugeriram,principalmente, $\mathrm{o}$ aprimoramento da navegabilidade para os links internos, o aperfeiçoamento da acessibilidade com exibição da próxima tela e tela anterior, e a incorporação de fórum nas postagens. A avaliação do Blog da $\mathrm{RCP}$, pelos experts de enfermagem, envolveu aspectos educacionais, interface do ambiente e recursos didáticos, demonstrados na tabela2.

Tabela 2 - Avaliação do Blog da RCP, segundo os experts de enfermagem, considerando seus domínios. Ribeirão Preto-SP, 2019. ( $n=11)$.

\begin{tabular}{lccc}
\hline \hline Domínio 1: Aspectos educacionais & Insatisfatório $\mathbf{n}(\%)$ & Satisfatório $\mathbf{n}(\%)$ & Excelente $\mathbf{n}(\%)$ \\
\hline Relevância do tema & 0 & 0 & $11(100)$ \\
Objetivos & 0 & $2(18,2)$ & $9(81,8)$ \\
Textos/ hipertextos & & $2(18,2)$ & $8(72,7)$ \\
Profundidade da abordagem & $1(9,1)$ & $1(9,1)$ & $10(90,9)$ \\
Clareza & 0 & 0 & $11(100)$ \\
\hline Coerência & 0 & $2(18,2)$ & $9(81,8)$ \\
Pertinência do vocabulário & 0 & $2(18,2)$ & $9(81,8)$ \\
Atualização e precisão dos conceitos & 0 & $1(9,1)$ & $10(90,9)$ \\
Pertinência dos links & 0 & $1(9,1)$ & $9(81,8)$ \\
Referências atualizadas e pertinentes & $1(9,1)$ & 0 & $11(100)$ \\
Autonomia & 0 & $1(9,1)$ & $10(90,9)$ \\
Coerência dos recursos & 0 & $1(9,1)$ & $10(90,9)$ \\
Pertinência dos recursos & 0 & 0 & $11(100)$ \\
Tipo de recursos & 0 & & $7(63,6)$ \\
Domínio 2: Interface do ambiente & & $4(36,4)$ & $9(90,9)$ \\
Navegabilidade & 0 & $2(18,2)$ & $7(63,6)$ \\
Acessibilidade & 0 & $4(36,4)$ & $10(90,9)$ \\
Menu & 0 & $1(9,1)$ & $10(90,9)$ \\
Ícones & 0 & $1(9,1)$ & "continua na página seguinte" \\
Botões & 0 & &
\end{tabular}




\begin{tabular}{|c|c|c|c|}
\hline Domínio 1: Aspectos educacionais & Insatisfatório n (\%) & Satisfatório n (\%) & Excelente $\mathrm{n}(\%)$ \\
\hline Design das telas & 0 & $3(27,3)$ & $8(72,7)$ \\
\hline Cores & 0 & $2(18,2)$ & $9(81,8)$ \\
\hline Fonte & 0 & $2(18,2)$ & $9(81,8)$ \\
\hline Densidade informacional & 0 & $4(36,4)$ & $7(63,6)$ \\
\hline \multicolumn{4}{|l|}{ Domínio 3: Recursos didáticos } \\
\hline Interatividade & 0 & $4(36,4)$ & $7(63,6)$ \\
\hline Apresentação de recursos & 0 & 0 & $11(100)$ \\
\hline Figuras & 0 & $3(27,3)$ & $8(72,7)$ \\
\hline Sons & 0 & $3(27,3)$ & $8(72,7)$ \\
\hline Fotos & 0 & $1(9,1)$ & $10(90,9)$ \\
\hline Simulação & 0 & $3(27,3)$ & $8(72,7)$ \\
\hline Vídeos & 0 & $1(9,1)$ & $10(90,9)$ \\
\hline Links externos & 0 & $1(9,1)$ & $10(90,9)$ \\
\hline Links internos & 0 & $2(18,2)$ & $9(81,8)$ \\
\hline Hipertextos & 0 & $1(9,1)$ & $10(90,9)$ \\
\hline Fórum (chats) & $3(27,3)$ & 0 & $8(72,7)$ \\
\hline E-mail & 0 & $1(9,1)$ & $10(90,9)$ \\
\hline
\end{tabular}

Fonte: dados obtidos do estudo, 2020.

Dentre um total de 32 tópicos avaliados pelos experts em enfermagem, a maioria foi considerada excelente. $\mathrm{O}$ domínio aspectos educacionais apresentou apontamentos insatisfatórios nos critérios "profundidade da abordagem"e"referências atualizadas pertinentes",tendo sido realizadas as devidas adequações,tanto no domínio "recursos didáticos" quanto,mais especificamente, no critério "fórum e chats", também sinalizado como insatisfatório e revisto para excelência do blog da RCP.

Os enfermeiros realizaram considerações acerca da profundidade da abordagem do tema, pertinência do vocabulário, atualização das referências, figuras e uso do fórum, o que também gerou nova avaliação e adequação pela pesquisadora.

O enfermeiro tem como papel primordial a educação em saúde, e esta deve ser pautada em abordagens pedagógicas atrativas e inovadoras ${ }^{(15)}$ Nessa perspectiva, a adoção de blogs educacionais é uma opção de fácil empregabilidade e acesso,interface agradável, didática, que permite a postagem desde um simples texto até construções complexas ${ }^{(16)}$.

$\mathrm{Na}$ área da enfermagem, estratégias tecnológicas de ensino e aprendizagem, encontram-se em franco desenvolvimento, embora a produção sobre as tecnologias educacionais existentes, e a construção e validação de objetos virtuais de aprendizagem tornaram-se expressivas somente a partir do ano de $2008^{(16-17)}$.

A qualidade apresentada em ferramentas educacionais inovadoras para o ensino da RCP possibilita o aprendizado autodirigido, sem restrições de tempo, local ou pessoal, que são os principais desafios dos cursos tradicionais atuais em enfermagem, o que torna o blog um objeto virtual de aprendizagem promissor na evolução da educação digital ${ }^{(18)}$.

Os especialistas em informática responsáveis por avaliar o blog em questão apresentaram formação e titulação profissional condizente com a proposta e um tempo de experiência suficiente, demonstrando amplo conhecimento e domínio quanto ao tema.

A experiência dos especialistas em informática para avaliar em face e o conteúdo plataformas da web e blogs de divulgação científica, como espaço virtual de aprendizagem, permitem a manutenção da qualidade de seu processo de elaboração, tornando a construção dessa ferramenta fidedigna e confiável ${ }^{(18)}$.

Com a mesma intencionalidade, os profissionais experts em enfermagem selecionados também demonstraram tempo de experiência profissional condizente com a proposta e, o fato de serem, na maioria, docentes em enfermagem, contribuiu para a facilidade e a acurácia no processo avaliativo dessa ferramenta educacional.

A utilização de instrumentos computacionais no processo de ensino e aprendizagem ocorre de maneira expressiva nos cursos de graduação em enfermagem, abrindo as portas para uso das tecnologias e indicando resultados estatisticamente significativos, que apoiam a adoção desse recurso educacional ${ }^{(19)}$.

Estudo quantitativo de caráter exploratório e descritivo, realizado com 14 acadêmicos do oitavo semestre de um curso de enfermagem, de uma universidade regional, situada no Noroeste 
do Estado do Rio Grande do Sul, objetivou identificar a influência de um blog, para o ensino de ventilação mecânica. O blog contribuiu, positivamente, para a construção e o processo de ensino e aprendizagem para enfermagem, aumentando o conhecimento dos estudantes e os motivando ${ }^{(20)}$.

Sobre a eficácia e a motivação da utilização de blogs para o ensino da enfermagem pesquisado, tipo relato de experiência, realizada em uma universidade pública, no estado do Ceará,envolvendo docentes e discentes de Mestrado em saúde, sobre a elaboração e aplicação de um blog para educação, nesse âmbito, evidenciou-se a satisfação dos participantes na utilização dessa ferramenta, recomendando-a como prática educativa atual, contextualizada e interdisciplinar ${ }^{(21)}$.

A PCR é intercorrência que demanda dos profissionais de enfermagem o conhecimento científico e a habilidade técnica para agir em tal situação, sendo recomendadas constantes atualizações e o aprofundamento científico quanto ao tema, o que pode ser facilitado por ferramentas educacionais inovadoras e tecnológicas, como o blog ${ }^{(8,22)}$.

Pesquisa realizada sobre o ensino híbrido da RCP com apoio de blog educativo, em universidade do Rio Grande do Norte, aberto para a população, identificou a utilização desse recurso pedagógico, utilizado na modalidade não presencial, como importante, abrangente e impactante, diante dos relatos identificados pelos participantes, considerando-o mecanismo prático e atrativo para a disseminação desse conhecimento $^{(23)}$.

Dessa forma, nota-se a viabilidade dos blogs para o processo de ensino e aprendizagem na enfermagem e no ensino da RCP frente à sociedade tecnológica digital, que demanda sujeitos e saberes que cooperem, mutuamente, para resolver problemas complexos, neste mundo de acesso quase imediato à informação ${ }^{(23-25)}$.

\section{CONCLUSÃO}

Obteve-se uma ferramenta virtual pedagógica de ensino e aprendizagem denominada Blog da RCP, sobre a ciência da ressuscitação cardiopulmonar de adultos, desenvolvendo-se as fases de análise, design, desenvolvimento, implementação e avaliação, além de ter sido realizada a validação desse objeto contemporâneo de aprendizagem em face e conteúdo.
As principais limitações foram: a ausência de avaliação do blog por estudantes em enfermagem e a incipiência de estudos que se propusessem a elaborar e validar blogs educativos para enfermagem, principalmente quanto à RCP.

Sugere-se a elaboração de mais pesquisas experimentais, bem delineadas, que se proponham testar a efetividade de blogs sobre o processo de ensino e aprendizagem da ressuscitação cardiopulmonar para enfermagem.

Esta pesquisa contribui para a ciência, a assistência e a educação em enfermagem, por apresentar uma ferramenta para o ensino da RCP, configurando aspecto novo e importante nesse âmbito, demonstrando o percurso metodológico de elaboração e validação, que pode ser replicado em outros ambientes de aprendizagem.

\section{REFERÊNCIAS}

1- ManianFA, HsuF. Writing to learn on the wards: Scholarly blog posts by medica Istudents and housestaff at a teaching hospital. Med Educ Online 2019;24(1):1565044. DOI: 10.1080/10872981.2018

2- Lillo-Bañuls A, Perles-Ribes JF, Fuentes R. Wiki and blog as teaching tools in tourism higher education. Journal of Teaching in Travel \& Tourism 2016;16(2):81-100.

DOI: 10.1080/15313220.2015.1118367

3- Amerson R. Using a global health blog to prepare nursing students for global nursing practice. Nurse Educ. 2020;49(2): E13-E14. DOI:10.1097/NNE.0000000000000703

4- Paterson QS, Thoma B, Milne WK, Lin M, Chan TM. A systematic review and qualitative analysis to determine quality indicators for health professions education blogs and podcasts. J Grad Med Educ. 2015;7(4):549-54. DOI: 10.4300/JGMED-14-00728.1

5- Reed SJ, Edmunds D. Use of a blog in an undergraduate nursing leadership course. Nurse Educ Pract. 2015;15(6):537-42. DOI: 10.1016/j.nepr.2015.07.010

6- Carley S, Beardsell I, May N, Crowe L, Baombe J, Grayson A, et al. Social-media-enabled learning in emergency medicine: a case study of the growth, engagement and impact of a free open access medical education blog. Postgrad Med J. 2017;94(1108):92-6. DOI: 10.1136/postgradmedj2017-135104

7- Costa IK, Costa IK, Dantas RA, Dantas DV, Nascimento JC, Costa RA, et al. Utilização da tecnologia no ensino a distância em suporte básico de vida. R-BITS 2018;8(2):67-77. DOI: 
10.18816/r-bits.v8i1.15558

8- Link MS, Berkow LC, Kudenchuk PJ, Halperin HR, Hess EP, Moitra VK, et al. Part 7: Adult advanced cardiovascular life support. Circulation 2015;132(18):S444-64.

DOI:

10.1161/CIR.0000000000000261

9- Thoma B, Chan TM, Paterson QS, Milne WK, Sanders JL, Lin M. Emergency medicine and critical care blogs and podcasts: Establishing aninternational consensus on quality. Ann Emerg Med. 2015;66(4):396-402. DOI: 10.1016/j.annemergmed.2015.03.002

10- Cheng A, Nadkarni VM, Mancini MB, Hunt EA, Sinz EH, Merchant RM, et al. Resuscitation education science: Educational strategies to improve outcomes from cardiac arrest: A scientific statement from the American Heart Association. Circulation 2018;138(6):e82-e122. DOI: 10.1161/CIR.0000000000000583

11- Fehring RJ.Methods to validate nursing diagnoses. Heart Lung 1987 [citado em 3 dez 2019]; 16(6):625-9. Available in: https://pdfs.semanticscholar.org/11f7/d8b02e02 681433695c9e1724bd66c4d98636.pdf

12- Filatro A. Design da interface humanocomputador. In: Filatro A. Design Instrucional na prática. São Paulo: Pearson Education do Brasil; 2008.

13- Krishnan R. Achieving cognitive skills in multimedia through revised bloom taxonomy. In: Mateev M, Poutziouris P (Eds). Creative business and social innovations for a sustainable future. New York: Springer; 2019.

14- Rodrigues RC, Peres HH. Desenvolvimento de ambiente virtual de aprendizagem em enfermagem sobre ressuscitação cardiorrespiratória em neonatologia. Rev Esc Enferm USP 2013;47(1):235-41. DOI: 10.1590/S0080-62342013000100030

15- Bastable SB. O enfermeiro como educador. 3a ed. Porto Alegre: Artmed; 2010.

16- Salminen L, Gustafsson ML, Vilén L, Fuster P. Nurse teacher candidates learned to use social media during the international teacher training course. Nurse Educ Today 2016;36:354-9. DOI: 10.1016/j.nedt.2015.08.026

17- Rocha EP, Oliveira AP, Esteves AV. Validação das tecnologias educacionais na área de Enfermagem: Uma revisão integrativa. Scientia Amazonia 2015 [citado em 3 dez 2019]; 4(3):41-7. Available in: http://scientia-amazonia.org/wpcontent/uploads/2016/06/v4-n3-41-47-2015.pdf 18- Almousa O, Prates J, Yeslam N, MacGregor D, Zhang J, Phan V, et al. Virtual reality simulation technology for cardiopulmonary resuscitation training: An innovative hybrid system with haptic feedback. Simul Gaming 2019;50(10):104687811882090. DOI: 10.1177/1046878118820905

19- Gonsalez EG, Lourenção LG. Experiências da utilização de instrumentos computacionais no ensino de graduação de enfermagem. Enferm Bras. 2016;15(6):315-22. DOI: 10.33233/eb.v15i6.720

20- Krause J, Braun D, Santos A, Fontana R. Influência de um blog no ensino de ventilação mecânica na disciplina de enfermagem no cuidado a pacientes de risco. Revista Contexto Educ. 2018;33 (105):95-118. DOI: 10.21527/21791309.2018.105.95-118

21- Aguiar AC, Guimarães JM, Ferreira HS, Almeida KT, Ribeiro TF, Anchieta TM, et al. Blog comoferramenta educacional: Contribuições para o processo interdisciplinar de educação em saúde. Rev Eletron Comun Inf Inov Saúde 2018;12(2):22031. DOI: 0.29397/reciis.v12i2.1301

22- Canova JC, Cyrillo RM, Hayashida M, Pompeo DA, Ribeiro RC, Dalri MC. Parada cardiorrespiratória e ressuscitação cardiopulmonar: Vivências da equipe de enfermagem sob o olhar da técnica do incidente crítico. Rev Enferm UFPE 2015;9(3):7095-103. DOI: 10.5205/reuol.7505-65182-1-RV.0903201511

23- Pinheiro OS, Alves CR, Feitosa MF, Morais VR, Silveira GM, Zanata IC, et al. Pioneirismo extensionista na universidade do estado do Rio Grande do Norte: Curso à distância em primeiros socorros e suporte básico de vida. Extensio: Revista eletrônica de extensão 2019 [citado em 3 dez 2019]; 16(32):2-11. Available in: https://periodicos.ufsc.br/index.php/extensio/art icle/view/1807-0221.2019v16n 32p2/ 39119

24- Mendonça NS, Fonseca NR, Aleluia I. O blog como ferramenta auxiliar no ensino aprendizagem da semiologia médica. Rev Inter Educ Saúde 2018 [citado em 3 dez 2019]; 2(1):114-6. DOI: 10.17267/2594-7907ijhe.v2i1.1885

25- Moura JG, Brito MP, Rocha GO, Moura LT. Conhecimento e atuação da equipe de enfermagem de um setor de urgência no evento parada cardiorrespiratória. J Res Fundam Care 2019 [citado em 3 dez 2019]; 11(3):634-40. Available in: https://pesquisa.bvsalud.org/portal/resource/pt/ biblio-994678

Nota: Este estudo foi extraído da dissertação de mestrado intitulada: Blog no ensino da ressuscitação cardiopulmonar: 
uma ferramenta para a formação do enfermeiro.

Recebido em: 20/01/2020

Aprovado em: 15/04/2020

Endereço de correspondência:

Denise Ferreira Gomide Batista

Rua Anselmo Marques Rodrigues, 801- Jardim Manoel Penna

CEP: 14098322 - Ribeirão Preto/SP-Brasil

e-mail: denisegomide@hotmail.com 